\title{
Estabilização de taludes marginais com técnicas de bioengenharia de solos no Baixo São Francisco
}

\author{
Francisco S. R. Holanda ${ }^{1}$, Igor P. da Rocha ${ }^{2} \&$ Vandemberg S. Oliveira ${ }^{3}$
}

\begin{abstract}
RESUMO
Os taludes marginais no baixo curso do Rio São Francisco, dominados por solos de baixa coesão sofrem com o avanço da erosão que causa recuo da margem e assoreamento do canal. A proposta deste trabalho foi estudar a aplicação da bioengenharia de solos visando ao controle da erosão por meio da estabilização dos taludes marginais, para posterior recuperação da vegetação ciliar. A área experimental foi dividida em dois tratamentos com 3 repetições, sendo o tratamento sem uso de bioengenharia (testemunha) implantado à montante do fluxo da água e o tratamento com uso de bioengenharia, à jusante. A técnica de bioengenharia de solos foi caracterizada pela associação do geotêxtil Fibrax ${ }^{\circledR} 400$ BF com gramínea Brachiaria decumbens, e retentores de sedimentos (Bermalongas ${ }^{\circledR}$ ) ao longo da linha d'água. Para avaliação do comportamento do talude realizou-se levantamento topográfico planialtimétrico aos 30, 180, 360 e 540 dias de implantação do experimento. No tratamento sem proteção de bioengenharia (testemunha) ocorreram variações significativas no perfil topográfico, enquanto no talude protegido com bioengenharia ocorreram movimentos de massa pouco expressivos.
\end{abstract}

Palavras-chave: erosão marginal, Rio São Francisco, geotêxtil

\section{Riverbank stabilization with soil bioengineering techniques at the Lower São Francisco River}

\begin{abstract}
The river banks of the Lower São Francisco River, which mostly present low cohesion soils, have suffered with the increase in erosion, leading to margin retreat and sedimentation. The purpose of this work was to study the application of a soil bioengineering technique in order to control the riverbank erosion by its stabilization aiming toward the riparian vegetation recovery. The experimental area was divided in two different assays, with three replications. The test assay (without the soil bioengineering technique) was installed upstream, and the assay with soil bioengineering was installed downsteam. The soil bioengineering technique was characterized by the association of the biotextile screen under the trade name Fibrax ${ }^{\circledR} 400 B F$, associated with Brachiaria decumbens grass and sediment retainers under the trade name Bermalonga ${ }^{\circledR}$, installed along the river bank base. In order to evaluate the riverbank changes, direct topographic measures was used. The data was collected 30, 180, 360 and 540 days after the beginning of the study. At the assay without soil bioengineering protection, strong slope soil mass movement occurred. The opposite behavior occurred in the assay with soil bioengineering, with a very little soil movement.
\end{abstract}

Key words: riverbank erosion, São Francisco River, biotextile

${ }^{1}$ Departamento de Engenharia Agronômica/UFS, Av. Mal Rondon s/n, Jardim Rosa Elze, CEP 49100-000, São Cristóvão, SE. Fone: (79) 2105-6988. E-mail: fholanda@infonet.com.br

${ }^{2}$ Mestrando em Agroecossistemas/UFS. Fone: (79) 2105-6988. E-mail: rochaigor@hotmail.com

3 Doutorando em Geografia/UFS. E-mail: vandemberg@ufs.br 


\section{INTRODUÇÃO}

Ocasionada pela implantação de grandes projetos hidrelétricos na Bacia do Rio São Francisco, a alteração no regime hídrico tem provocado, no seu baixo curso, um avançado processo erosivo, através do solapamento da base do talude marginal, devido ao abaixamento do nível d’água e do desmatamento da vegetação ripária. Estradas, lotes residenciais e agrícolas têm sido destruídos pelo acelerado processo erosivo levantado em 57 focos, caracterizado pela desestabilização dos taludes nas margens do rio São Francisco, conforme relato de Casado et al. (2002) e Holanda et al. (2005).

O controle da erosão marginal se apresenta de diversas formas, a exemplo do uso de enrocamentos que, embora com boa eficiência, são bastante onerosos, impossibilitando o seu uso de forma ampla, em toda a margem do rio. De maneira empírica, os ribeirinhos se têm valido de várias soluções, como do uso de pneus, palha de coco, sacos de areia e vários materiais sintéticos, como mantas de polietileno que além de não produzirem o efeito desejado no controle da erosão, trazem problemas para a recuperação da vegetação ciliar e degradam a paisagem, importante componente de atrativo turístico na região (Bandeira, 2005). Surge, então, a possibilidade de, usando-se matéria-prima abundante na área, testar soluções que possam ser justificadas economicamente e sobre a qual se tenha eficiência comprovada, através de ensaios experimentais.

A bioengenharia de solos, através do uso de mantas de fibra de coco recobertas com uma malha de polipropileno fotodegradável, associada a retentores de sedimentos, começa a se apresentar como solução de possível viabilidade no controle da erosão marginal (Gomes et al., 2005). Na Europa, os primeiros trabalhos referentes a esta técnica, tradicionalmente empregada no controle dos processos erosivos em morros e encostas, datam do século XVII; ela consiste no uso de elementos biologicamente ativos em obras de estabilização do solo e sedimentos (Sutili et al., 2004), porém Gray \& Sotir (1996) relatam em seus estudos utilizando a bioengenharia de solos em margens de corpos d’água, o uso de estruturas rígidas para a proteção da faixa de oscilação da cota do rio, a exemplo de enrocamentos, gabiões e colchões-reno. Estas opções tornam as margens artificiais e originam conseqüências diretas sobre a ictiofauna que utiliza a faixa mais próxima do talude para alimentação, abrigo ou reprodução (Petts, 1987). Com efeito, os elementos biologicamente ativos podem ser conjugados a elementos inertes como: rochas, concreto, madeira, ligas metálicas, polímeros naturais e sintéticos, biotêxteis dentre outros (Schieltz \& Stern, 1996).

Este trabalho objetivou estudar técnicas de bioengenharia de solos visando ao controle da erosão por meio da estabilização dos taludes marginais para posterior recuperação da vegetação ciliar.

\section{MATERIAL E MÉTODOS}

Os ensaios experimentais foram conduzidos na margem sergipana do Baixo São Francisco, próximo ao Perímetro
Irrigado Cotinguiba-Pindoba, município de Propriá, estado de Sergipe, que apresenta clima tipo megatérmico, característico do semi-árido brando, com temperatura média anual de $26{ }^{\circ} \mathrm{C}$ e período chuvoso nos meses de março a agosto, com precipitação média anual de 806,1 mm ano-1. O solo do sítio experimental possui granulometria composta em mais de $90 \%$, de areia média, fina e muito fina, sendo classificado como Neossolo Flúvico, conforme Casado et al. (2002). A Classificação textural foi realizada como orienta Georio (2000).

As áreas, previamente identificadas com focos de erosão, foram avaliadas com relação à possibilidade de implementação das técnicas de bioengenharia de solos associadas à recomposição da vegetação ripária. Os critérios escolhidos para a condução dos ensaios, dentre os vários trechos de margem que apresentam a problemática da erosão, foram: área, altura e declividade do barranco, uso do solo, cobertura vegetal, distância do canal principal do rio e textura do solo.

\section{O sítio experimental}

A área estudada apresenta marco georeferenciado com as coordenadas UTM 744.301,092 E / 8868.461,918 N, na qual se identificou uma grande concentração de focos de erosão em margem quase que completamente desmatada. O talude apresentou declividade média de 34\%, altura de 3,35 m, com dimensões de $127 \mathrm{~m}$ de comprimento por $11 \mathrm{~m}$ de largura, perfazendo uma área total de $1.397 \mathrm{~m}^{2}$. O sítio experimental foi dividido em duas áreas semelhantes, no sentido montante e a jusante do rio: área testemunha (sem bioengenharia) com $57 \mathrm{~m}$ de comprimento, e tratamento com bioengenharia, com $70 \mathrm{~m}$ de comprimento.

A implantação dos elementos de bioengenharia de solos ocorreu no mês de julho de 2004, iniciada com a suavização manual de todo o talude. Utilizou-se o geotêxtil Tela FIBRAX ${ }^{\circledR} 400 B F$ e o retentor de sedimentos Bermalonga ${ }^{\circledR}$ D40 (Deflor, 2005). O geotêxtil fotodegradável empregado é composto de $100 \%$ de fibra de coco, entrelaçada por uma malha de polipropileno fotodegradável; este geotêxtil possui, como característica, a degradação em um período entre 48 e 60 meses, de modo a propiciar proteção inicial e incorporar matéria orgânica ao solo, ao longo do tempo; o mesmo foi aplicado longitudinalmente sobre o talude, fixado com grampos de aço em forma de "V" com 0,2 m de comprimento e 0,042 m de diâmetro. Na porção destinada ao tratamento com uso de bioengenharia de solos foi semeada a gramínea Brachiaria decumbens, para promover uma rápida cobertura vegetal do talude e fixação do geotêxtil.

Visando à recuperação da vegetação ciliar foram plantadas, dentro do perímetro experimental. mudas de espécies florestais nativas da região: tamboril (Enterolobium contortisiliquum (Vellozo) Morong), canafístula (Cassia grandis L. f.), pau-ferro (Caesalpinia leiostachya (Bentham) Ducke), aroeira vermelha (Schinus terebinthifolius Raddi.), pau-pombo (Tapirira guianensis Aubl.) e mulungu (Erythrina velutina Willd.).

Os retentores de sedimentos utilizados eram compostos por fibras vegetais desidratadas e prensadas, envolvidas pela 
mesma malha de polipropileno fotodegradável, com $0,4 \mathrm{~m}$ de diâmetro e comprimento padrão igual a 1,7 m. Esses retentores de sedimentos foram fixados na base do talude, com estacas de maçaranduba cada uma, nas dimensões 1,1 m de comprimento, 0,05 $\mathrm{m}$ de largura e 0,05 $\mathrm{m}$ de espessura. As estacas foram posicionadas na extremidade e inseridas no meio dos retentores de sedimentos, utilizados para promover a redução do impacto do fluxo e refluxo das ondas na base do talude, evitando o solapamento e a exposição às variações diárias da cota do rio.

\section{Avaliação dos ensaios experimentais}

Para a avaliação do comportamento do talude, realizouse a coleta dos dados topográficos de forma direta, através de levantamento planialtimétrico, nas seções estabelecidas na área experimental. Durante esta etapa foram efetuados 4 levantamentos na área de estudo, aos 30, 180, 360 e 540 dias de implantação do experimento e, através da locação topográfica de um perfil longitudinal e seções transversais (Figura 1), o avanço do processo erosivo pôde ser mensurado utilizando-se o método de levantamento planialtimétrico por irradiação para geração do modelo digital do terreno (Espartel, 1980); utilizou-se também uma estação total marca Trimble, modelo 3303 DR e assessórios como prisma, tripé, piquete e trena. Realizou-se o levantamento por irradiação a partir do marco implantado no sítio experimental e georeferenciado com receptores GPS (Global Positioning System) geodésico PROMARK2, medindo-se as distâncias horizontais, as distâncias inclinadas e as diferenças de nível dos pontos de interesse. Por fim, foram mensuradas 6 seções transversais com eqüidistância de 20 m entre elas.

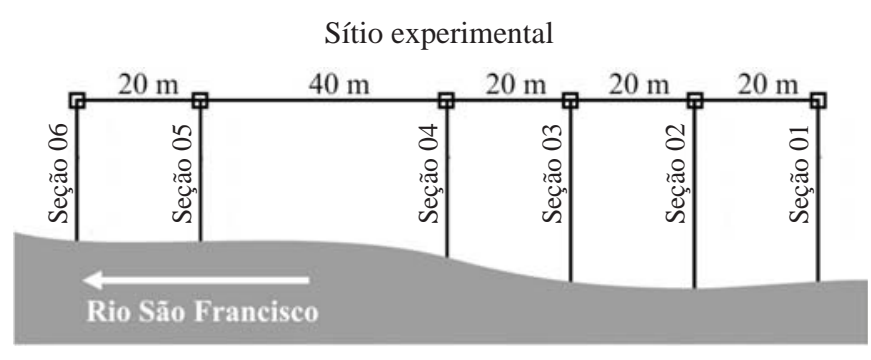

Figura 1. Esquema de locação das seções transversais no sítio experimental

A confecção dos perfis, análise e interpretação dos dados obtidos em campo e tratamento das imagens foram realizadas no laboratório de Erosão e Sedimentação do Departamento de Engenharia Agronômica da Universidade Federal de Sergipe, com auxílio dos softwares Autocad 2002 (Autodesk Incorporation, 2001), Corel Draw 11 (Corel Corporation, 2002) e Photoshop 5.5 (Adobe Systems Corporation, 1999), o primeiro para a confecção e os demais para tratamento das imagens referentes às seções transversais.

\section{RESULTADOS E DISCUSSÃO}

O solo que compõe o talude marginal apresenta muito baixa coesão, baixa resistência ao cisalhamento e baixo ân- gulo de atrito (de 17 a $25^{\circ}$ ), além de Fator de Segurança (FS) menor que 1,0 classificado como instável (Santos, 2002). A composição granulométrica do sítio experimental, composta em mais de $90 \%$ de areia média, fina e muito fina (Tabela 1), foi um dos fatores responsáveis pela instabilidade do talude, tornando-o favorável ao desmoronamento por cisalhamento. Uma vez que as areias se apresentam predominantemente finas, são consideradas mal graduadas, razão por que contribuem no entrosamento e, conseqüentemente, o ângulo do atrito é menor. Segundo Barata (1984), ângulo de atrito é o ângulo de repouso ou ângulo de talude natural ou, ainda, o ângulo formado entre um plano horizontal e a tangente à superfície de ruptura do talude.

Tabela 1. Granulometria $\left(\mathrm{g} \mathrm{kg}^{-1}\right)$ do sítio experimental

\begin{tabular}{crrrrrrrr}
\hline $\begin{array}{c}\text { Porção } \\
\text { do } \\
\text { talude }\end{array}$ & $\begin{array}{c}\text { Seixos e } \\
\text { Grânulos }\end{array}$ & $\begin{array}{c}\text { Areia } \\
\text { muito } \\
\text { grossa }\end{array}$ & $\begin{array}{c}\text { Areia } \\
\text { grossa }\end{array}$ & $\begin{array}{c}\text { Areia } \\
\text { média }\end{array}$ & $\begin{array}{c}\text { Areia } \\
\text { fina }\end{array}$ & $\begin{array}{c}\text { Areia } \\
\text { muito } \\
\text { fina }\end{array}$ & Silte & Argila \\
Superior & 0,7 & 0,3 & 2,8 & 312,3 & 228,0 & 406,9 & 27,3 & 21,7 \\
Médio & 38,0 & 14,0 & 83,0 & 411,0 & 138,4 & 340,0 & 62,0 & 35,1 \\
Inferior & 5,8 & 22,5 & 82,4 & 365,5 & 130,0 & 369,8 & 20,0 & 4,0 \\
\hline
\end{tabular}

Os trabalhos foram conduzidos em um trecho com alto fluxo d’água, além de estar bastante próximo ao canal principal do rio. O material erodido foi carreado para o curso d'água ou distribuído na porção inferior do talude, soterrando ou tombando as mudas de espécies florestais plantadas.

Na realização da caracterização morfométrica do sítio experimental verificou-se que, em função da proteção oferecida ao talude, ocorreu variação no volume de material erodido e o processo erosivo atua de forma diferenciada no tempo e no espaço. As seções transversais no tratamento sem bioengenharia de solos apresentaram grandes variações em sua forma, ao longo do monitoramento (Figura 2).

As variações de perfil topográfico que ocorreram nas seções 1,2 e 3 se devem à baixa coesão do solo, assim como incipiente cobertura vegetal, vulnerabilizando esta faixa à ação das ondas, embora tenham apresentado comportamentos distintos entre si. A seção 1 apresentou menos efeitos do processo erosivo, fato explicado pela menor declividade e maior comprimento de rampa, uma vez que a declividade do terreno e o comprimento de rampa influenciam na intensidade da tensão cisalhante. Nas seções 1, 2 e 3, ocorreu rebaixamento do topo do talude. A grande massa de solo movimentada na seção 3 pode estar relacionada às alterações geomorfológicas de ajuste do canal fluvial.

As seções 2 e 3 foram muito erodidas e apresentaram perfis transversais bastante alterados, principalmente pela ação do embate das ondas na base do talude, levando à verticalização da margem. Na seção 2, a ausência de proteção física afetou o talude, sendo possível verificar alteração no perfil, no período de setembro de 2004 a março de 2005. A seção 3 mostrou a maior perda de solo quando comparada com as seções 1 e 2, distantes 20 e 40 m respectivamente. A alta declividade nas seções 2 e 3 (33\%) influenciou o processo erosivo estabelecendo uma relação direta entre declividade do talude e corrasão da base, o que acarretou 

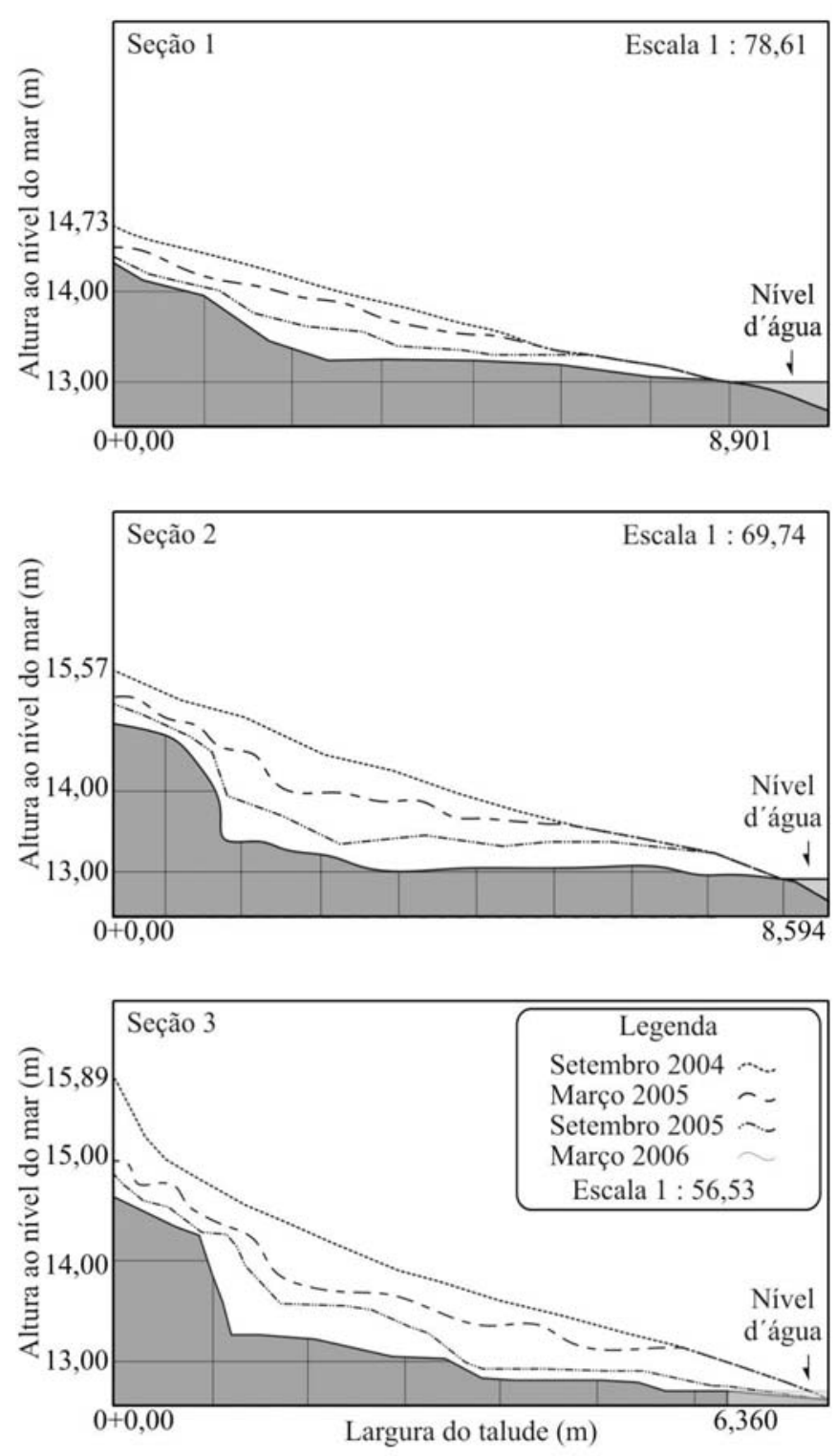

Figura 2. Comportamento multitemporal das seções 1, 2 e 3, no tratamento sem uso de bioengenharia de solos

expressivos movimentos de massa por meio de desmoronamentos por cisalhamento. O talude que, inicialmente, apresentava declividade média de $33 \%$, passou a se mostrar verticalizado. Esta situação tem, em conseqüência, levado a freqüentes movimentos de massa com queda de grandes blocos a partir do solapamento da base, promovido pelo cisalhamento. A tensão cisalhante é influenciada pela declividade do talude e pelo comprimento da rampa pois, quanto maior a declividade e menor o comprimento de rampa, mais intensa será a tensão cisalhante (Pruski, 2006). As forças de fluxo e refluxo do embate constante de ondas na base do talude causaram um processo acelerado de solapamento que, neste tratamento, desencadeou o desmoronamento de blocos devido ao baixo valor do Fator de Segurança (FS), igual a 0,667. O Fator de Segurança (FS) é resultante do quociente entre forças resistentes e forças atuantes no talude e considera um talude instável quando o valor do Fator de Segurança (FS) é inferior à unidade (Santos, 2002).
Na seção 4 o processo erosivo foi menor que nas seções 1, 2 e 3, mesmo localizada imediatamente ao lado da seção 3 , com maior intensidade de erosão. Na seção 5, onde ocorreram severos danos ao geotêxtil, observou-se desmoronamento por basculamento apresentando, porém, um talude morfologicamente semelhante ao início das avaliações. O rebaixamento do topo do talude foi bastante reduzido quando comparado com o tratamento sem uso de bioengenharia. No tratamento com uso de bioengenharia de solos é perceptível a importância dos elementos vivos e inertes na proteção física do talude contra os efeitos da erosão marginal. O geotêxtil contribuiu para a estabilização do talude e mostrou eficiência no controle da erosão das margens, no período avaliado. Apesar dos danos ocasionados pelo pisoteio de animais de grande porte, esta proteção oferecida pelo geotêxtil bem fixado ao solo, associada à presença de vegetação herbácea, propiciou a existência de ambiente favorável à estabilização do talude. O pouco rebaixamento do topo do talude observado na seção 5 está intimamente ligado à proteção física oferecida pelos elementos de bioengenharia nos terços inferiores do talude, reduzindo a massa de solo erodido para o curso d'água. Predominantemente, nos locais em que o geotêxtil se encontrava em bom estado de conservação, foi possível observar a estabilização do solo da margem permitindo o desenvolvimento da espécie Brachiaria decumbens e de outras herbáceas autóctones.

A seção 6 se assemelha à seção 4; entretanto, por estar localizada na porção final do tratamento com bioengenharia de solos (Figura 1), mostrou efeitos do processo erosivo instaurado imediatamente após o experimento. Mesmo apresentando maior declividade, o volume de solo perdido por erosão foi menor que nas seções do tratamento sem uso de bioengenharia de solos. O comportamento multitemporal das seções 4, 5 e 6 está representado na Figura 3.

O geotêxtil exerceu, em parte, a função de diminuir a corrasão do solo com menor agravamento do processo de solapamento da base do talude, mantendo a declividade constante nas seções 4, 5 e 6 . Observou-se grande diferença do recuo da margem entre os dois tratamentos, assim como do processo e distribuição da erosão no talude, destacada pela resistência do geotêxtil aos movimentos de massa, demonstrada pela perda de mudas das espécies florestais plantadas, causadas pela erosão do solo nas duas áreas estudadas.

A gramínea Brachiaria decumbens contribuiu para o recobrimento da área com geotêxtil, da base até o topo do talude e para a estabilização física do solo, fixação do geotêxtil e enriquecimento orgânico do solo, embora tenha apresentado pouca adaptabilidade à submersão na época das cheias e também pouca renovação no período de estiagem. No tratamento protegido com a bioengenharia de solos as espécies herbáceas (B. decumbens e espécies autóctones) formaram uma densa cobertura vegetal do solo e uma grande rede de raízes que auxiliaram, na fixação do geotêxtil e a estabilização das camadas superficiais do talude, concordando com Coelho et al. (2001) que afirmam que essa forma de vegetação teve importante contribuição na prevenção da erosão do solo em condições de chuvas simuladas. O conjunto geotêxtil - solo - vegetação herbácea - mudas de arbóreas, 

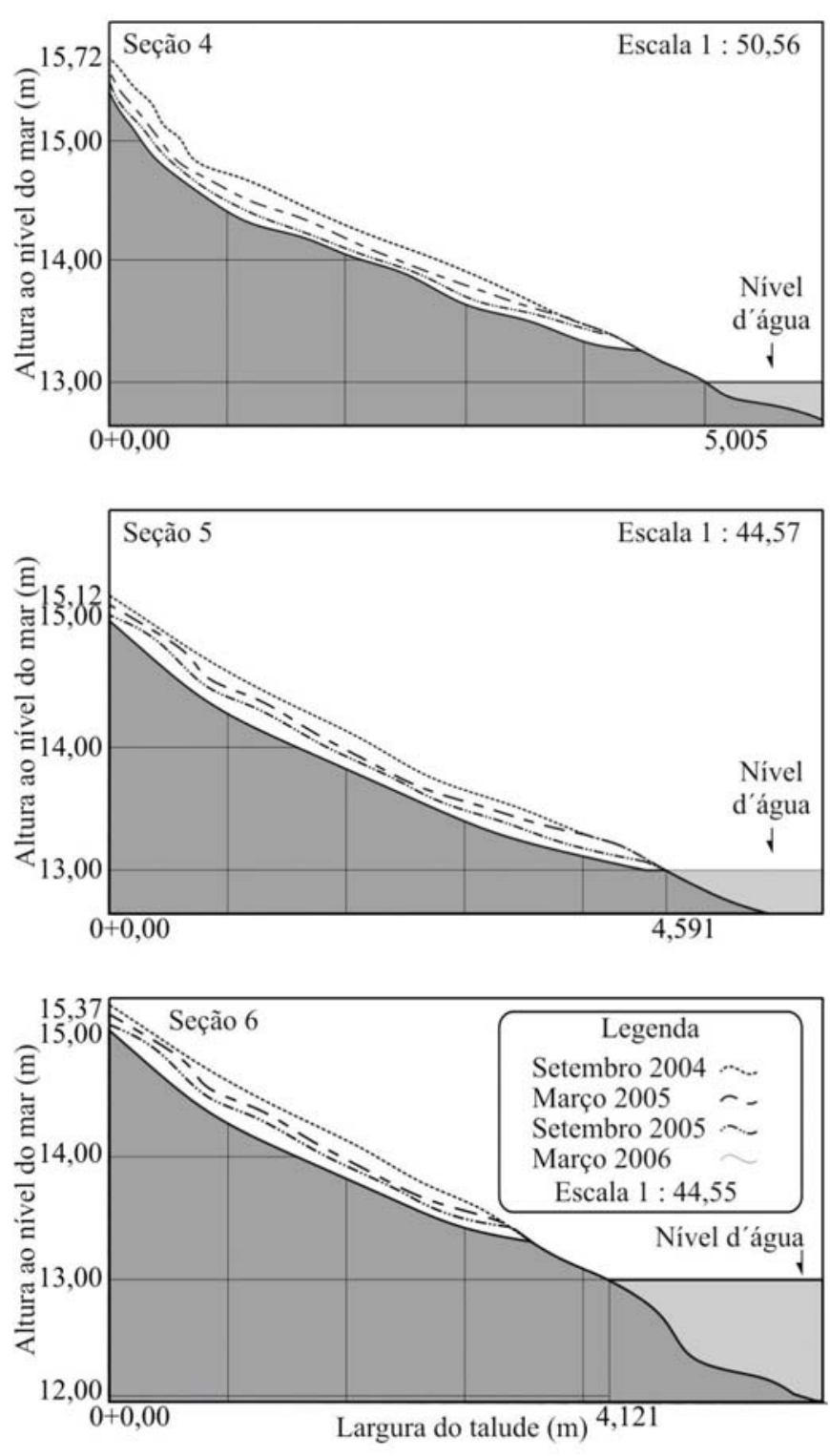

Figura 3. Comportamento multitemporal das seções 4, 5 e 6, no tratamento com uso de bioengenharia de solos

gerou um substrato resistente e estruturado, que contribuiu sobremaneira no processo de estabilização do talude (Durlo \& Sutili, 2005). As gramíneas nativas presentes na base do talude, fisiologicamente adaptadas à condição de inundação, merecem destaque em virtude de suportarem eventos de inundação e estiagem durante todo o período de experimentação, porém se observou serem altamente exigentes em umidade, se desenvolvendo satisfatoriamente na faixa de inundação constante.

Os retentores de sedimentos utilizados não se mostraram adequados, já que não demonstraram resistência ao movimento de fluxo e refluxo das ondas. A inserção de estacas promoveu rasgos na malha que recobre o cilindro de palha, promovendo o seu desmanche nos primeiros meses. A quantidade de retentores de sedimentos instalados, formando apenas uma linha, também foi insuficiente para promover a proteção esperada. A proteção da margem com os retentores de sedimentos na linha d'água durante o período em que estes se apresentavam intactos, mostrou-se importante no controle inicial da erosão marginal; após sua destruição, o solapamento foi reiniciado na base do talude. Por ser ponto vulnerável, a base do talude necessita de uma proteção mais efetiva, o que sugere a utilização de materiais mais resistentes.

Devido à alta pluviosidade em seu alto curso no período de fevereiro a abril de 2005, o baixo curso do rio São Francisco teve sua vazão aumentada em mais de $100 \%$ para a época, passando da média de $1.800 \mathrm{~m}^{3} \mathrm{~s}^{-1}$ para $4.000 \mathrm{~m}^{3} \mathrm{~s}^{-1}$ no início de março; com o que, a cota do rio foi alterada de 3,0 para 5,5 m, aumentando a intensidade dos movimentos de massa nas margens degradadas. Este aumento de vazão, mesmo contribuindo para o avanço da erosão por encontrar, na área experimental um talude em processo de estabilização, propiciou teste da resistência do geotêxtil aos movimentos de massa promovidos naquele período; desta forma, se observou que a elevação da cota do rio ocasionou o avanço da erosão de forma bastante acelerada e expressiva na área sem geotêxtil, destruindo boa parte da área plantada com espécies florestais, comprovando a relativa resistência do conjunto de elementos de bioengenharia de solos.

\section{CONCLUSÕES}

1. A bioengenharia de solos é um método facilitador do desenvolvimento da vegetação ciliar além de eficiente como ferramenta para diminuição na taxa de erosão por corrasão e posterior solapamento da base do talude marginal.

2. O uso de materiais que se degradam gradativamente é interessante, pois possibilita resgatar com a maior fidelidade possível, o equilíbrio geomorfológico e ecológico do rio, tornando a recuperação ambiental das margens mais efetiva.

3. A constância da cota elevada do rio, acima do esperado para a época, por um período de tempo maior ou igual a 180 dias, foi fator agravante para acelerar o processo de remoção de partículas de solo, promovendo corrasão e conseqüente desmoronamento de blocos.

\section{AGRADECIMENTOS}

Os autores agradecem à FAPITEC - Fundação de Amparo à Pesquisa e a Inovação Tecnológica do Estado de Sergipe, e a empresa DEFLOR Bioengenharia.

\section{LITERATURA CITADA}

Adobe Systems Corporation. Adobe photoshop, version 5.5: Project planning software, 1999. CD-Rom

Autodesk Incorporation. AutoCAD 2002, version 15.2: Project planning software, 2001. CD-Rom

Bandeira, A. A. Evolução do processo erosivo na margem direita do Rio São Francisco e eficiência dos enrocamentos no controle da erosão no trecho em estudo. São Cristóvão: UFS, 2005. 155p. Dissertação Mestrado 
Barata, E. F. Propriedades mecânicas dos solos. Rio de Janeiro: LTC, 1984. 152p.

Casado, A. P. B.; Holanda, F. S. R.; Araújo Filho, F. A. G.; Yaguiu, P. Bank erosion evolution in São Francisco River. Revista Brasileira de Ciência do Solo, v.26, p.231-239, 2002.

Coelho, A. T.; Galvão, T. C. B.; Pereira, A. R. The effects of vegetative cover in the erosion prevention of a road slope. Environmental Management and Health, v.12, n.1, p.78-87, 2001.

Corel Corporation. Corel Draw, version 11.633: Project planning software, 2002. CD-Rom

DEFLOR - Defesa Florestal Ltda. Catálogo de produtos e serviços de bioengenharia. Belo Horizonte: Deflor, 2005. 26p.

Durlo, M. A.; Sutili, F. J. Bioengenharia: Manejo biotécnico de cursos de água. Porto Alegre: EST Edições. 2005. 189p.

Espartel, L. Curso de Topografia. 7.ed. Globo: Porto Alegre, 1980. 655p.

Georio. Manual Técnico de Encostas: Análise e investigação. Rio de Janeiro: Fundação Instituto de Geotécnica do Município do Rio de Janeiro, 2000. 253p.

Gomes, L. G. N.; Holanda, F. S. R.; Anjos, I. R. dos; Rocha, I. P. Bioengenharia na estabilização de talude marginal e restauração ambiental da margem no baixo curso do Rio São Francisco. In: Congresso de Ecologia do Brasil, 7, 2005, Caxambu. Anais... Caxambu: CEB, 2005. CD Rom
Gray, D. H; Sotir, R. Biotechnical and soil Bioengeneering Slope Stabilization. New York: John Wiley, 1996. 378p.

Holanda, F. S. R.; Santos, I. G. da C.; Santos, C. M. dos S.; Casado, A. P. B.; Pedrotti, A. Riparian fragments affected by bank erosion in the Lower São Francisco River, Northeastern Brazil. Revista Árvore, v.29, n.2, p.148-152, 2005.

Petts, G. E. Time-scales for ecological change in regulated rivers. In: Craig, J. F.; Kemper, J. B. (eds). Regulated streams. Advances in ecology. New York: Plenum, p.257266, 1987.

Pruski, F. F. Conservação de solo e água: práticas mecânicas para o controle da erosão hídrica. Viçosa: UFV, 2006. 240p.

Santos, C. M. A. Erosão no Baixo São Francisco Sergipano e os mecanismos de desestabilização dos taludes na margem do rio. São Cristóvão: UFS, 2002. 158p. Dissertação Mestrado

Schieltz, H. M.; Stern, R. Ground bioengineering techniques for slope protection and erosion control. Oxford: Blackwell Science, 1996. 186p.

Sutili, F. J.; Durlo, M. A.; Bressan, D. A. Potencial biotécnico do sarandi-branco (Phyllanthus sellowianus Müll. Arg.) e vime (Salix viminalis L.) para revegetação de margens de cursos de água. Ciência Florestal, v.14, n.1, p.13-20, 2004. 